\title{
De la línea clara al movimiento perpetuo: realismo y dinamismo en la adaptación cinematográfica de Las aventuras de Tintín de Steven Spielberg
}

\author{
From a Clear Line to a Perpetual Motion: Realism \\ and Dynamism in the Film Adaptation of \\ The Adventures of Tintin by Steven Spielberg
}

\author{
VÍCTOR AERTSEN \\ Universidad Carlos III de Madrid \\ vaertsen@db.uc3m.es \\ ORCID ID: 0000-0002-3946-7519
}

Resumen: Las aventuras de Tintín es una de las series más célebres en la historia del cómic. Entre las diversas adaptaciones audiovisuales de la obra de Hergé destaca la película Las aventuras de Tintín: El secreto del unicornio (2011), dirigida por Steven Spielberg utilizando tecnología motion capture. Este artículo reflexiona sobre algunos de los retos y las soluciones cinematográficas utilizadas por el director estadounidense para adaptar el característico estilo visual y narrativo de Hergé a la gran pantalla. Partiendo de declaraciones de los propios creadores y de teóricos de ambos medios, la investigación analiza el proceso de negociación estilístico emprendido por Spielberg a partir de dos conceptos estéticos claves en ambas obras: realismo y dinamismo.

Palabras clave: adaptación cinematográfica, cómic, realismo, dinamismo, movimiento de cámara, motion capture, expresividad.

\begin{abstract}
The Adventures of Tintin is one of the most famous series in comic history. Among the various audiovisual adaptations of Hergé's work, the film The Adventures of Tintin: The Secret of the Unicorn (2011), directed by Steven Spielberg using motion capture technology, stands out. This article reflects on some of the challenges and cinematographic solutions used by the director to adapt Hergé's characteristic visual and narrative style to the big screen. Based on statements of the creators and theorists of both media, the research analyzes the process of stylistic negotiation undertaken by Spielberg in relation to two key aesthetic concepts: realism and dynamism.
\end{abstract}

Key words: Film adaptation, comic, realism, dynamism, camera movement, motion capture, expressiveness. 


\section{LAS AVENTURAS DE TINTÍN}

Las aventuras de Tintín se ha convertido en una de las series más célebres en la historia del cómic. Creado por el historietista belga Hergé, seudónimo de Georges Prosper Remi, desde que al reportero protagonista se le levantó por primera vez su icónico tupé al acelerar un descapotable en una de las tiras que conformarían el primer álbum de la serie, Tintín en el país de los Soviets (1929), iniciaría una carrera perpetua que le llevaría a recorrer todo el globo terráqueo - y la Luna- a lo largo de 23 álbumes y una historia inacabada al morir el autor en 1983.

Publicado originalmente en forma de tira en el semanal juvenil del diario belga Le Vingtième Siècle, alcanzó la madurez estilística en El Loto Azul (1935), quinto álbum de la serie y punto de inflexión metodológico a partir del cual la obra de Hergé, en palabras de Daniela Dorfman (2020: 223), «pasa de la mirada fugaz y superficial del exotismo, incluso del racismo, a la documentación e investigación que van a cambiar sus propios posicionamientos y el tono y la densidad de la representación».

Las aventuras del joven reportero ganarían especial notoriedad cuando dio el salto al periódico diario Le Soir entre 1941 y 1944, época en la que se publican algunas de sus aventuras más conocidas y reconocidas, entre las que se encuentran El cangrejo de las pinzas de oro (1941), El secreto del Unicornio (1943) y El tesoro de Rackham el Rojo (1943). Pero será tras la posguerra cuando la serie se convierta en un fenómeno floreciente, alcanzando el éxito internacional al iniciarse su publicación en varios idiomas extranjeros, empezando por la traducción en 1952 de El secreto del Unicornio al castellano, inglés y alemán (Farr, 2001). Desde entonces, la serie se ha traducido a más de 60 lenguas (Grossman, 2011).

El éxito internacional propiciaría múltiples proyectos de adaptación a la pequeña y gran pantalla, tanto en animación como en acción real. El primero llegó en 1947 de la mano de Claude Misonne, El cangrejo de las pinzas de oro (Le crabe aux pinces d'or), adaptación cinematográfica en blanco y negro del álbum del mismo nombre realizada en stop-motion, resultando una película de gran encanto, pero estilísticamente alejada del dinamismo y la expresividad de la obra original.

Entre 1957 y 1962, el estudio belga Belvision Studios recurriría a la animación tradicional para adaptar a la televisión diez de las aventuras de Hergé a lo largo de 103 episodios de cinco minutos de duración bajo el título Las aventuras de Tintín, por Hergé (Les Aventures de Tintin, d'après Hergé). Dirigida por Ray Goossens y escrita por el artista del cómic belga Greg, la mayoría de las historias de la serie sufrieron cambios significativos respecto a las tramas de los álbumes originales (Lofficier y Lofficier, 2002: 143-144), iniciando una tendencia hacia la adaptación libre del universo tintinesco que se repetiría en películas posteriores.

Es el caso de las primeras adaptaciones en acción real, la francesa Tintín y el misterio del Toisón de Oro (Tintín et le mystère de la toison d'or, Jean-Jacques Vierne, 1961) y la franco-española Tintín y el misterio de las naranjas azules 
(Tintin et les oranges bleues, Philippe Condroyer, 1964), ambas realizadas a partir de guiones originales de André Barret en colaboración con Rémo Forlani, a los que se sumarían Condroyer y René Goscinny en el segundo título. Si bien el esfuerzo por mimetizar a los actores con el aspecto de los personajes reales resultaría reseñable, el resultado produce una tensión constante entre realidad y artificio difícil de salvar, siendo imposible obviar que uno se encuentra ante actores de carne y hueso disfrazados para la ocasión. Además, como apunta Jordi Revert (2013: 23), en ambos casos «el artificio pretendidamente cómic de las cintas [...] chocaba con la sencillez bidimensional del estilo Hergé, siempre más eficaz y expresivo, dotado de una cinética y una agilidad narrativa que estas no conseguían implantar en sus imágenes».

Al final de la década, Belvision apostaría nuevamente por la animación tradicional para llevar a cabo su primera adaptación cinematográfica de la obra de Hergé, la celebrada Tintín en el templo del sol (Tintin et le temple du soleil, Eddie Lateste, 1969), que adaptaba con mayor rigor dos álbumes originales, Las siete bolas de cristal y El templo del sol. Ello no impediría que poco después el mismo estudio realizara una segunda película de animación, Tintín en el lago de los tiburones (Tintin et le Lac aux requins, Raymond Leblanc, 1972), esta vez a partir de un guion original de Greg.

Finalmente, la adaptación de las aventuras del reportero alcanzaría mayor éxito de crítica y público con la serie animada para televisión Las aventuras de Tintín (Les Aventures de Tintin), coproducida entre 1991 y 1992 por el estudio francés Ellipse Programme y el canadiense Nelvada. Dirigida por Stéphane Bernasconi, la serie adaptaría 21 de los libros originales a lo largo de 39 capítulos, siguiendo los álbumes originales hasta tal punto que los paneles del original a menudo se trasladaron directamente a la pantalla (Lofficier y Lofficier, 2002).

Este recorrido ayuda a entender el contexto creativo en el que Steven Spielberg desarrollará su proyecto, cuyo planteamiento continúa alguna de las tendencias y busca evitar algunos de los errores cometidos en las adaptaciones previas.

\section{LAS AVENTURAS DE SPIELBERG}

Spielberg descubrió la existencia de Tintín durante el estreno de Indiana Jones en busca del arca perdida (Raiders of the Lost Ark, 1981), al comparar recurrentemente la crítica europea su película con las aventuras del reportero belga. Atraído por una saga de cómics que, en sus propias palabras, funcionaban «como una película» (Grossman, 2011), negoció la cesión de los derechos y empezó a trabajar en un primer guion, pero terminaría descartando el proyecto al considerar que no estaban consiguiendo «interpretar a Hergé en un grado que sería aceptable para los furibundos fans globales» de la obra original (Galloway, 2011). Tendrían que pasar dos décadas hasta que el director encontrase en la tecnología de 
captura de movimiento (motion capture) «el medio en el que [le] gustaría contar la historia» (Grossman, 2011).

Fascinado por el trabajo de Peter Jackson y su equipo de Weta Digital en la trilogía de El Señor de los Anillos (The Lord of the Rings, 2001-2003), decidió contar con ellos y desarrollar la traslación del universo de Hergé a la gran pantalla mediante esta tecnología. El proyecto originalmente contemplaba la creación de una franquicia que incluiría la adaptación de varios álbumes de la saga en sucesivas películas firmadas por Spielberg y Jackson. Pero, a pesar de los múltiples rumores y las declaraciones de los propios autores sobre su intención de retomarla (Elvy, 2020), hasta el momento el proyecto de adaptación de la obra de Hergé ha consistido únicamente en una película, estrenada en 2011 bajo el título Las aventuras de Tintin: El secreto del unicornio (The Adventures of Tintin: Secret of the Unicorn).

El grueso del guion de la película, encargado a Edgar Wright, Steven Moffat y Joe Cornish, se inspira en tres álbumes de la saga: El cangrejo de las pinzas de oro (noveno álbum de la serie), El secreto del Unicornio (undécimo) y El tesoro de Rackham el Rojo (duodécimo). Si bien, según el director, su intención era «combinarlos en una especie de estructura en tres actos» (Galloway, 2011), el proceso se realiza tomando grandes licencias respecto a los materiales originales, invirtiendo el orden de las dos primeras historias, añadiendo algunos pasajes de acción que en las obras originales Hergé resolvía con una elipsis o paralipsis y, sobre todo, introduciendo un tercer acto totalmente inventado y cargado de acción en la línea de un blockbuster contemporáneo de acción-aventuras.

Con estas licencias, el director buscaría encontrar un punto de equilibrio que permitiera complacer a los fans de toda la vida y, a la vez, crear un producto que apelara a un público más amplio (Bartlett, 2012). Es importante recordar en este sentido que los libros de Hergé «nunca han sido más que una excentricidad eurófila marginal en los Estados Unidos» (O’Hehir, 2011) y, como bien apunta Geraghty (2007: 453),

[...] gran parte del éxito y el atractivo de Spielberg para el público cinematográfico es que ofrece momentos cinematográficos familiares y entretenidos que se basan en sus trabajos anteriores y recuerdan a los espectadores que están viendo una película de Spielberg.

El material original es un importante punto de partida narrativo, estético e incluso publicitario en manos de un director que ha construido buena parte de su filmografía a partir de adaptaciones que le permiten explotar «la viabilidad cultural del material ya probado en el mercado para atraer la atención del público y simplificar la publicidad» (Hunter, 2017: 213). Pero Spielberg no duda en llevarse el universo de Hergé a su terreno para dotarlo de un mayor alcance comercial e imprimir en el mismo su sello personal, ofreciendo una suerte de «versión de Spielberg» que funciona como una «promesa específica de diferencia, así como de calidad» (Hunter, 2017: 213) entre sus propios fans. 
Si bien durante la campaña de promoción de la película Spielberg adoptaría «conscientemente una posición de fan para persuadir a los demás de que su obra es auténtica, fiel y consciente del texto original que la inspiró» (Geraghty, 2017: 456), la película está trufada de pequeños guiños tanto para los fans de Tintín como para los del propio director (Grossman, 2011). Y lo que es más importante, a medida que la narración avanza, el universo de Hergé se ve progresivamente contagiado por la espectacularidad narrativa de la saga Indiana Jones, franquicia de aventuras que sin duda marca el horizonte de expectativas de los fans del director e inevitablemente sería tomada como punto de partida para valorar las virtudes y los defectos de la nueva cinta por parte de la crítica (Lyons, 2011) ${ }^{1}$.

De este modo, según O’Hehir (2011), el deseo de apelar a un público global lleva a Spielberg a traducir «la visión del mundo ingenua, idealista y distintivamente europea de la era colonial» característica de la obra de Hergé «a un idioma más familiar, básicamente el de Indiana Jones». En cualquier caso, si tanto el universo de Hergé (Dorfman, 2020) como las primeras películas de Indiana Jones (Berlatsky, 2011) han sido criticadas por sus estereotipos raciales y por ofrecer una visión colonialista de los países «exóticos» en los que se desarrollan sus aventuras, la adaptación de Spielberg se presenta como una versión calculadamente vaciada, ya no solo de estereotipos, sino directamente de representaciones racializadas. «En aras de la sensibilidad», según Berlatsky (2011), el director termina ofreciendo «un mundo más monocromático» que «no es racista ni antirracista, sino simplemente soso» desde el punto de vista de las representaciones raciales, evitando cualquier posible controversia para erigirse como un producto fácilmente comercializable a un público global.

En cualquier caso, a pesar de estas licencias, resulta innegable el esfuerzo de Spielberg por buscar soluciones cinematográficas que le permitieran adaptar el característico estilo visual y narrativo de Hergé al medio audiovisual sin perder de vista el referente original (Bartlett, 2012; Nguyen, 2012; Revert, 2013). Con el fin de profundizar en este proceso, en los siguientes apartados se analiza el trabajo de adaptación a partir de dos categorías estéticas claves, realismo y dinamismo, que el propio Hergé y otros autores han traído a colación en múltiples ocasiones al hablar de su obra y que ayudan a entender el compromiso estético alcanzado por Spielberg con la obra original.

\footnotetext{
${ }^{1}$ Uno de los hitos de la campaña de promoción de la película tendría lugar en la Comic-Con de San Diego de 2011, escenario en el que Spielberg aprovecharía la oportunidad para posicionarse como fan de Hergé a la vez que se celebraba el 30 aniversario de Indiana Jones en busca del arca perdida por parte de la amplia comunidad de fans de la saga (Geraghty, 2017).
} 


\section{REALISMO}

\subsection{Tridimensionalidad: de la ligne claire al motion capture}

Considerado el padre de la «línea clara» (ligne claire), el estilo del autor belga privilegia la claridad, la expresividad y la uniformidad de la línea, con trazos finos, colores lisos y una sencillez bidimensional que facilitan la legibilidad del dibujo. Para ello, trabaja realizando «calcos sucesivos» (Pierre Sterckx, 1991: 20) sobre sus bocetos, un método que le permite simplificar progresivamente la línea hasta alcanzar unos dibujos cuidadosamente compuestos donde cada objeto, personaje, acción y reacción están claramente delineados y donde el contenido de cada viñeta se articula con precisión con el resto de las imágenes del panel.

Spielberg descartó desde un primer momento la transliteración gráfica de los cómics de Hergé, lo que en un sentido estricto implicaría copiar los dibujos originales y animarlos rellenando los huecos entre las viñetas, como hicieron anteriormente las series de animación. La película iba a rodarse en 3D, por lo que el universo de la misma debía ser tridimensional, y el director estaba decidido a que la obra resultante tuviera el realismo de una película de acción real. De este modo, Spielberg se enfrentó al reto de encontrar un equilibrio entre realismo tridimensional y la iconicidad de los cómics originales, actualizándolos sin perder de vista la referencia original.

Como las adaptaciones previas en acción real habían demostrado, la estilización hacia el cómic de un universo completamente fotorrealista producía una sensación extraña en la obra, introduciendo un artificio difícilmente obviable por parte del espectador. Según el director, mantener una cierta referencialidad icónica realizando un rodaje con acción real obligaría a un diseño de personaje al estilo de Dick Tracy (Warren Beatty, 1990), donde las prótesis hacían que las caras de los actores resultaran prácticamente irreconocibles y excesivamente estilizadas, lo que restaba naturalidad a la obra (Galloway, 2011). «Queremos que las aventuras de Tintín tengan la realidad de una película de acción real», explicaba el director en 2008, pero «sentimos que filmarla en un formato tradicional de acción real simplemente no honraría el aspecto distintivo de los personajes y el mundo que creó Hergé» (Brown, 2008).

Como se ha avanzado, la solución vendría de la mano de Peter Jackson y su equipo de Weta Digital, decantándose Spielberg por la recreación completa del universo diegético mediante CGI y tecnologías de captura de movimiento. Según el propio director: «Nos parecía que la acción real resultaría demasiado estilizada para que una audiencia se identificara con ella. [...] El vestuario parece encajar mejor cuando el medio elegido es digital» (Bettinger, 2011). La tecnología ofrecía las posibilidades expresivas que Spielberg buscaba para reproducir el estilo visual de Hergé a un universo tridimensional. Al usarla, según Peter Jackson, los actores «dan vida a los personajes con toda la destreza e integridad de una actuación en vivo en la que las Imágenes Generadas por Ordenador funcionan a la manera de un maquillaje digital»(Guise, 2011: 14). La actuación de los personajes 
funcionará como un boceto original sobre el que, de forma similar al proceso de «calcos sucesivos» de Hergé, los diseñadores irían progresivamente depurando la imagen hasta alcanzar el resultado final deseado.

Escogida la tecnología, quedaba por definir el grado de realismo. Si bien claramente pictórico y en gran medida icónico, Hergé busca en sus viñetas un compromiso entre la sencillez y la claridad de sus imágenes -elementos denotativos que expresen lo esencial, ligera tendencia a la caricatura para dotar de personalidad a los personajes- y la verosimilitud de las mismas, especialmente en el caso de los elementos que rodean a los personajes objetos, vehículos y paisajes dibujados con sencillez, pero con realismo-. Con sus fondos, el dibujante belga buscaba introducir «un toque de veracidad suplementaria» (Hergé, 1991: 14) en sus imágenes, para lo que recurre, junto a sus colaboradores, a fotografías, revistas especializadas e incluso viajes de estudio. Basta revisar las viñetas de las primeras páginas del cómic original de El secreto del Unicornio (Hergé, 1990b) para comprobar el grado de detalle que alcanzan los fondos de la escena del mercadillo.

Esta verosimilitud de los entornos no ha pasado desapercibida a los teóricos de la novela gráfica, que encuentran en ella un recurso esencial en el planteamiento estético del autor. Según McCloud (1993: 42-43), el estilo visual de Hergé «combina personajes muy icónicos con fondos inusualmente realistas», una combinación que «permite a los lectores enmascararse en el personaje y adentrarse de forma segura en un mundo sensualmente estimulante». Por su parte, Matthew Screech (2005: 28) señala que a través del carácter mimético del «realismo Hergeliano», el autor «hacía plausible la historia: creaba la ilusión de que el triunfo del héroe ocurría en el mundo real». Aun así, el historietista belga tenía siempre mucho cuidado, en sus propias palabras, de «no recargar el dibujo ni saturarlo con detalles superfluos», buscando a la vez «hacer el máximo de simplificaciones y guardar el máximo de fidelidad al estilo general» (Hergé, 1991: 14).

Por otro lado, en las novelas gráficas las características del medio facilitan el proceso de simplificación de los fondos al permitir que los dibujantes jueguen con las dimensiones de los marcos de cada viñeta para limitar el encuadre de las mismas y que buena parte de ellos se vean ocultados tras los bocadillos en los que se insertan los diálogos. Esta flexibilidad o elasticidad del marco en el cómic pone de relieve, según Groensteen (2013: 40), «la rigidez del aparato cinematográfico, que está prácticamente condenado a dotar a la imagen proyectada de una forma fija y constante». La necesidad de exhibir con mayor profusión los fondos en los que se mueven los personajes dificultaría que se pudiera llevar a cabo un trabajo de simplificación similar al de Hergé, dando una mayor presencia y un mayor peso al entorno de los personajes en las composiciones.

Para alcanzar el grado buscado tanto de realismo como de fidelidad al original, el equipo de Weta trabajó más de tres años para diseñar el mundo de Tintin, «no solo mirando lo que dibujó Hergé», según Peter Jackson, 
«sino rastreando las influencias del mundo real que usó en su proceso de diseño» (Guise, 2011: 14). A través de esta riqueza de detalles, los espacios no solo cumplen la función de caracterizar a los personajes que los habitan -el piso de Tintín, el camarote de Haddock, la mansión de Sakharine--, sino también, en palabras de Frank Victoria, diseñador de Weta Workshop, la de «crear un ambiente más interesante para el desarrollo de la acción» (Guise, 2011: 107).

Para evitar contrastes de diseño entre personajes y fondo, la omnipresencia de unos fondos realistas forzaría que el diseño de los personajes también tendiera hacia el realismo. Se podría argumentar que, en el marco del compromiso entre realidad e iconicidad antes mencionado, si Hergé acercaba el estilo de dibujo de sus fondos a la iconicidad de sus personajes, que por su peso visual en la viñeta funcionan como punto de referencia, en el caso de la adaptación cinematográfica Spielberg se vería en la necesidad de buscar este equilibrio acercando el diseño de los personajes al realismo de sus fondos.

El principal reto en el diseño de personajes era conseguir que fueran reconocibles como los personajes de Hergé y, a la vez, cuerpos tridimensionales que se mueven en un entorno realista. En palabras de Joe Letteri, supervisor de efectos visuales de la película, «tenía que parecer real, pero tenías que mirar hacia atrás a lo que habías visto en la página» (Giardina, 2011). Matt Aitken (Frei, 2011), otro de los supervisores de efectos visuales, lo explica de la siguiente manera:

Desde el principio queríamos honrar el diseño que Hergé creó para sus personajes, ese look característico. Pero nuestros personajes también tenían que existir de manera creíble en el mundo que estábamos creando para ellos: un mundo muy detallado de realidad idealizada. Usamos rasgos faciales exagerados y las proporciones de los personajes de los cómics con sus cabezas y manos de gran tamaño para llevar la apariencia de los personajes de Hergé al mundo de la película. Pero hicimos que los detalles de los personajes fueran naturales: las texturas de su piel, la forma en que se movían sus rostros cuando hablaban y especialmente sus ojos están mucho más cerca de los humanos reales que de su forma en general.

Si bien este proceder es susceptible de producir un efecto de «disonancia visual» en los espectadores dada «la disparidad de la forma de la caricatura y el detalle de la superficie» (Carter, 2019: 5), cabe argumentar que la búsqueda de la combinación en general armónica entre estos dos regímenes estéticos está en consonancia con el planteamiento original de Hergé de combinar licencias icónicas en el dibujo de los personajes y tendencias realistas en el entorno (McCloud, 1993: 42-43).

Spielberg hace explícito este reto en la escena que abre la película. Un caricaturista callejero que guarda un parecido más que razonable con Hergé se encuentra retratando a un personaje que se presenta de espaldas al espectador, aunque no es difícil intuir que se trata del intrépido reportero. 
A sus pies se encuentra Milú, al que la cámara sigue en una breve digresión por el mercadillo para introducir al espectador algunos elementos dramáticos y exhibir por primera vez los ricos detalles del universo digital construido. No será hasta el momento en que el retratista entregue su obra terminada y el espectador se encuentre ante un retrato del Tintín bidimensional de los cómics cuando el Tintín tridimensional se gire y desvele por primera vez su rostro, demandando la valoración comparativa entre retrato y «original».

Además del obvio homenaje por parte de Spielberg, es posible interpretar el gesto como una forma de apuntar hacia «la autoconciencia del conflicto que se impone al conferir relieve dimensional a la obra gráfica» (Jordi Revert, 2013: 72) e incluso una sugerencia irónica a que «los cómics podrían ser una adaptación de los eventos de la película», apuntando en este sentido a que, quizás, «la película es más "real" que los libros» (Barlett, 2012: 12). Pero sin lugar a dudas, la escena actúa como una invitación a transitar desde la acostumbrada imagen icónica del personaje a su nuevo aspecto tridimensional, que acompañará al espectador de aquí en adelante. Una imagen más realista de lo usual, pero en consonancia con un entorno de «realidad idealizada» colmado de detalles y por el que el director ha paseado previamente la mirada del espectador, con cierto regusto exhibicionista, mientras seguía a Milú por el mercadillo.

\subsection{Expresividad: del símbolo convencional al gesto visual}

En la escena del caricaturista, la extensa expresión de satisfacción que esboza Tintín al mostrar su retrato bidimensional contrasta significativamente en su desarrollo con la sonrisa estática del dibujo, lo que, sumado al giro combinado de cámara y cuerpo, pone de manifiesto que el reto al que se enfrentaban los creadores no era solo de carácter icónico, sino también expresivo. La inclinación de Spielberg y el equipo de Weta por unas texturas faciales detalladas vendría motivada por el deseo de integrar estas facciones de forma verosímil en un mundo tridimensional de «realidad idealizada», pero esas facciones debían ser además capaces de transmitir la enorme energía expresiva que Hergé consigue con sus trazos.

Según relata Marco Revelant, supervisor de modelos de Weta Digital, las primeras versiones del diseño del personaje de Tintín se ceñían al diseño original, pero pronto se dieron cuenta de que esta versión «no era capaz de proporcionarnos el registro completo de expresiones que nuestra película realista necesitaba» (Guise, 2011: 36). Los diseñadores se vieron obligados a encontrar un equilibrio entre la sencillez icónica de los dibujos originales y una textura más realista de sus cuerpos, especialmente los rostros, dotándolos de una estructura muscular, arrugas y otros elementos que ayudaran a expresar emociones.

Los rostros debían además ser portadores del amplio abanico de «sensogramas» a los que Hergé y muchos otros autores recurren habitualmente para «expresar la irradiación energética emanada por la 
persona» (Gasca y Gubern, 2001: 230). Estos signos, que le permitían dotar a sus viñetas de gran dinamismo y fuerza expresiva con una gran economía de trazos, a la vez facilitan que las figuras no se vean deformadas por intereses expresivos, pero no encajaban dentro del universo tridimensional ideado por Weta Digital. «El papel de las finas líneas de acción, las marcas de movimiento, las estrellas y las gotas de sudor que son claves esenciales para comunicar acción y tensión», según Joe Letteri (Guise, 2011: 16), «debía ser asumido por los propios personajes». Este reto se hace explícito igualmente al comienzo de la película, en los títulos de crédito, que Spielberg colma de estos símbolos para subrayar su importancia y frecuencia en la obra de Hergé, poniendo de relieve su posterior omisión en el universo tridimensional de la película.

La decisión tendría consecuencias significativas sobre la adaptación del cómic a la pantalla en términos compositivos, ya que las facciones de los personajes adquieren una mayor importancia que en la obra original. En el caso de los cómics, los sensogramas permiten a Hergé no solo simplificar el dibujo de sus personajes, sino presentar muchos momentos emocionalmente importantes sin mostrar sus caras. En la película, en cambio, las facciones de los personajes se convierten en la principal vía por la que se comunican sus emociones, ganando protagonismo.

Compárese, por ejemplo, la escena en la que Tintín descubre al llegar a casa que la maqueta del barco ha desaparecido. En el cómic de El secreto del Unicornio, Hergé presenta el evento de forma sucinta en dos viñetas: una primera en la que se observa al personaje entrando en casa, seguido por otra en la que descubre con sorpresa que el barco ha desaparecido. A pesar de la importancia del descubrimiento, Hergé se permite no mostrar la cara de Tintín, recurriendo a su gesto corporal y a las marcas de sudor que emanan de su cabeza para comunicar el estado emocional del personaje. La solución le permite dirigir la atención del lector hacia la repisa vacía, que tan solo unas viñetas atrás, durante el transcurso de otra escena de composición prácticamente simétrica, estaba ocupada por la maqueta.

En la película, en cambio, el descubrimiento se resuelve compositivamente desde una perspectiva prácticamente invertida: la cámara se aproxima a la repisa para mostrarla en primer plano, presentando al personaje atónito en segundo plano y de frente, con la mirada dirigida hacia el lugar donde debería estar la maqueta. La solución compositiva permite al espectador observar con total claridad cómo se esboza una expresión de sorpresa en el rostro, imagen que Spielberg complementa, tras un cambio de perspectiva, con un primer plano del personaje en el que se prolonga y matiza su reacción.

Además de posibilitar que los personajes desarrollaran expresiones y movimientos muy naturales, miméticos a los de los actores que los interpretan, la tecnología de captura de movimiento también permite al director trascender la propia actuación para enfatizar determinados movimientos expresivos o corporales. Según declaraciones de Spielberg, le 
permitía «reducir o sobrescribir una actuación y, a través de los animadores, poner [algo en una actuación] que ni siquiera los actores trajeron al [set]» (Carter, 2019: 5). El director y su equipo se decantarían de este modo por una suerte de expresividad intensificada, aceptable en el ámbito de la animación, pero de marcado contraste con las viñetas de Hergé, donde la carga expresiva se divide entre las facciones, el cuerpo y, especialmente, los signos externos a los personajes.

Hergé recurre también en sus obras a uno de los recursos propios del cómic que, según el teórico Thierry Groensteen (2013: 153), permiten «acentuar» la acción dentro del «sistema espacio-tópico» de la página: la colocación de eventos importantes en la última viñeta de una página. Se trata de una posición estratégica, especialmente en los cómics con disposiciones regulares de las viñetas, ya que supone un punto en el que el movimiento de lectura de las sucesivas imágenes que componen la página se detiene momentáneamente antes de pasar al siguiente panel. En el caso de la escena analizada, situada en el cómic original al final de la página 6 , este acento se ve intensificado por la composición de la viñeta y su relación con las imágenes previas: mientras que en las viñetas inmediatamente anteriores el autor establece un intenso movimiento de progresión lectora a través de las composiciones -utilizando recursos que se detallarán en los próximos apartados: composiciones orientadas de izquierda a derecha y cargadas de acción-, en la última viñeta el cuerpo de Tintín esboza un respingo hacia la izquierda que actúa como una fuerza contrapuesta al movimiento de lectura previo, solicitando al lector que se detenga momentáneamente en el evento representado, que funciona, además, como la resolución de las acciones anteriores. Valiéndose de los recursos propios del medio, Hergé modula de este modo el movimiento de lectura por el espacio de la página para acentuar la viñeta final y potenciar expresivamente su contenido.

Algo parecido hace Spielberg en la misma escena, pero valiéndose en su caso de los recursos propios del medio cinematográfico: el movimiento de la cámara en el espacio y de los personajes en relación con la cámara. El descubrimiento de la desaparición del barco por parte de Tintín no solo se presenta en la película con el personaje de frente, sino que se produce en el momento en el que la cámara finaliza un largo movimiento que ha llevado al espectador desde una posición elevada en la esquina contraria de la habitación hasta situarle detrás de la cómoda en la que debía encontrarse el barco. Así, de forma equivalente al cómic original, Spielberg dispone la acción para que la revelación coincida y por tanto se vea acentuada por un cambio en el ritmo del movimiento del espectador por el espacio - diegético en este caso-, potenciando la expresión corporal y facial esbozada por el personaje. La cámara empuja al espectador a lo largo de la habitación hacia el encuentro de la expresión facial del personaje.

Esta acentuación se ve a su vez reforzada por el movimiento corporal del personaje, que desarrolla un largo desplazamiento por la habitación de forma similar y sincrónica al movimiento de cámara para terminar 
deteniéndose ante la cámara en el momento de la revelación. Desvelada la desaparición, el director prolonga la reacción de Tintín a lo largo de otro plano tomado desde una posición inversa, al que corta aprovechando un enfático movimiento de rotación corporal del personaje que le vuelve a situar en primer plano frente a la cámara. De este modo, la movilidad de la cámara y del personaje se ponen al servicio de la expresión emocional, no solo al posibilitar y guiar la atención hacia sus facciones, sino mediante movimientos que enfatizan la carga expresiva de la situación.

\section{DINAMISMO}

\subsection{Movilidad: del multimarco a la cámara en movimiento}

A pesar de la aparente sencillez de sus dibujos, las viñetas de los cómics originales son el resultado de un largo proceso de «calcos sucesivos» a través de los cuales, en palabras del propio Hergé (1991: 12), persigue que el trazo resultante sea a la vez «el más ágil y el más expresivo, así como el más claro y también el más sencillo, el que mejor expresa el movimiento». Esta última idea resulta fundamental para entender la obra del autor belga, ya que, como recuerda Revert (2013: 72), «si por algo se caracterizaba el estilo de Herge era por su efectividad cinética, capaz de imprimir una sensación de acción y movimiento constante a partir de viñetas prácticamente limpias». Será esta una cuestión central a la hora de valorar cualquier adaptación de su obra, máxime teniendo en cuenta que, según apunta Nick Nguyen (2012: 109), los intentos previos demostraban una «incapacidad para traducir con éxito al cine el sentido dinámico de la narración gráfica de Hergé».

Trazo, composición y puesta en página colaboran en las obras originales de Hergé para dotar a la narración de este «sentido dinámico» o «efectividad cinética». Desde un punto de vista estructural, Hergé dispone sus páginas siguiendo el modelo típico del cómic franco-belga, que el teórico Thierry Groensteen (2007, 2013) denomina disposición en forma de "gofrera» (waffle-iron). Este modelo, que en el caso de la obra de Hergé se concreta en páginas compuestas por cuatro tiras horizontales con una media de tres viñetas por tira, establece una densidad y regularidad en la disposición de las imágenes en la página que fomenta la sensación de avance o variación de la narrativa visual. Por un lado, la densidad de la disposición hace un uso intensivo del «multimarco» (multiframe), que Groensteen (2013: 136) identifica como el «aparato emblemático del medio»:

El multimarco atrae al lector siempre hacia adelante, designa de antemano las imágenes que están por llegar; el lector, por lo tanto, se siente convocado por ellas y corre precipitadamente tras los siguientes segmentos narrativos, como si bajara corriendo un tramo de escaleras. Ansioso por descubrir las sorpresas que le deparan, pero también, de alguna manera, por agotar el propio aparato, por llegar al final, por no perderse nada.

El modelo clásico de gofrera, si bien flexible, produce viñetas de tamaño reducido, lo que fuerza que las acciones e interacciones de los personajes en 
una misma escena se descompongan en sucesivas viñetas. Para avanzar en la narración, el lector se mueve incesantemente por el espacio de la página, de una viñeta a otra, y por el espacio diegético representado en las mismas, ya que cada nueva viñeta muestra, como mínimo, un pequeño desplazamiento de los personajes o una mínima variación del propio encuadre para adaptarlo al nuevo intervalo de acción.

Por otro lado, este avance promovido por la densidad se ve complementado por el efecto sobre el ritmo de lectura inducido por la regularidad de su disposición, que por su organización en bandas horizontales «impone a los paneles una alineación que facilita el barrido de la mirada» (Groensteen, 2007: 47) y por su estabilidad impone una cadencia que «hace que el lector sienta que cada paso (cada panel) lo acerca a ese final ineludible» (Groensteen, 2013: 144). De este modo, combinando densidad y regularidad, en la obra de Hergé «la atracción magnética del aparato (la serie de cuadros múltiples) se ve acentuada por la regularidad metronómica con la que se desarrolla la acción» (Groensteen, 2013: 144), fomentando una sensación de avance inexorable en el lector.

En el caso de las aventuras de Tintín, este movimiento de avance se ve además facilitado por el estilo característico del autor. La claridad de sus trazos y sus colores lisos, que el propio Hergé (1991: 16) defiende por otorgar «una mayor "legibilidad" a los dibujos», facilitan que el lector embarcado en la narración fluya a través de las imágenes sin detenerse más allá del tiempo estrictamente necesario para captar la información más relevante para la narración. Tras haber ubicado a los personajes en un entorno realista al comienzo de la escena, esta legibilidad se ve facilitada adicionalmente por su tendencia a reducir o eliminar completamente los detalles espaciales de sus fondos en las sucesivas viñetas en las que se desarrolla la acción dramática. El autor recurre además de forma habitual, aunque generalmente sutil, a símbolos cinéticos o «movilgramas» (Gasca y Gubern, 2001: 194) como «expresión metonímica del movimiento» de los personajes por el espacio, dotando a la narración de una inexorable sensación de movilidad. Y, por último, como señala el propio Hergé (Groensteen, 2007: 48), sus composiciones se caracterizan por seguir una «regla absoluta» sencilla pero efectiva, observable en toda su obra:

[...] en nuestro país se lee de izquierda a derecha. [...] Cuando muestro un personaje que está corriendo, generalmente va de izquierda a derecha, en virtud de esta simple regla; y luego eso se corresponde a un hábito del ojo, que sigue el movimiento y que acentúo: de izquierda a derecha, la velocidad parece más rápida que de derecha a izquierda. Utilizo la otra dirección cuando un personaje vuelve sobre sus pasos.

Esta regla no solo se aplica al movimiento de los personajes, sino en general a todas las acciones que implican una dirección - mirar, señalar, vigilar, descubrir, aproximarse- o un suceso fuera de campo - una llamada telefónica, una caída. 
Todos estos recursos colaboran en la escena del cómic en la que Tintín encuentra la maqueta del barco en el mercadillo. A pesar de desarrollarse en un mismo espacio, la disposición en gofrera y los recursos estilísticos mencionados dotan a la escena de gran empuje narrativo: las imágenes son fáciles de leer, en las viñetas centrales se ha omitido detallar el fondo para facilitar una lectura más rápida, una de las viñetas muestra un sutil tirabuzón en el suelo a modo de movilgrama para reforzar la sensación de movimiento de los personajes, los cuerpos presentan una orientación de izquierda a derecha -incluso cuando Tintín mira hacia la izquierda, entendemos que está mirando «hacia atrás», quedando marcada la composición por la dirección hacia la derecha del cuerpo de Sakharine-, la acción se descompone en múltiples fragmentos que fuerzan al espectador a moverse incesantemente de una porción a otra de la página y la perspectiva sobre la acción varía ligeramente de viñeta a viñeta para ajustarse a los personajes relevantes en cada intervalo.

Teniendo en cuenta que el trabajo constante de descomposición y variación de las viñetas «produce un efecto análogo al que se produce en una película, un zoom o un movimiento de cámara (travelling, panorámica)» (Groensteen, 2007: 42), quizás no sea de extrañar que la solución propuesta por Spielberg para adaptar el «sentido dinámico» de la narración gráfica de Hergé se fundamente en el uso enfático del movimiento de cámara. A través de la hipermovilidad de la cámara, Spielberg consigue superar el reto de «dar un impulso cinético a las imágenes estáticas» (Corliss, 2011), convirtiendo la película, según la crítica, en «una ingeniosa adaptación cinetizada» (Weber, 2011) de los cómics originales, «una máquina de movimiento perpetuo» (Cabin, 2012).

En su adaptación de la escena anterior en el mercadillo, la narración mueve constantemente al espectador por el espacio mediante sucesivos cortes y movimientos de cámara, reencuadrando la acción según van apareciendo e interactuando los diferentes personajes. A pesar de tratarse de una escena que podría haberse resuelto de forma prácticamente estática, Spielberg combina montaje y movimiento de cámara para producir una puesta en escena de composición cambiante en la que cada nuevo intervalo informativo de la secuencia, que en el cómic motivaría el cambio de viñeta, se desarrolla en un encuadre diferente dentro de la película, produciendo un efecto similar al cambio de viñeta. Para conseguirlo, la puesta en escena alcanza en ocasiones tintes coreográficos, realizando cámara y personajes giros sobre su propio eje que carecen de cualquier motivación dramática, pero aseguran una movilidad incesante del punto de vista del espectador sobre el espacio. La película produce de este modo un efecto de progresión constante afín al impulso dinámico de los cómics originales, si bien adaptado al medio cinematográfico, moviendo al espectador por el espacio diegético de forma similar a como lo hacía Hergé con su lector por el espacio de la página. 
Esta movilidad de la cámara se ha visto posibilitada por la propia tecnología utilizada durante la producción. Según declaraciones de Spielberg (Galloway, 2011), la cámara se manejaba mediante un dispositivo que «parece un controlador de un videojuego, con una pequeña pantalla de televisión y un control X e Y para mover la cámara de un lado a otro», lo que le permitía «caminar con esta pequeña herramienta ligera, cambiando de ángulo constantemente» e incluso «introducirme en el set, porque mientras no estuviera usando un traje de captura de movimiento, las cámaras no me veían». Grabar se convierte así en un proceso parecido a un juego, por el cual el director, inmerso en el centro de la acción, se ve incitado a moverse por el set y cambiar constantemente la posición de los personajes y la cámara en el espacio para ofrecer a cada intervalo una nueva perspectiva sobre la acción dramática.

Por otro lado, el movimiento de cámara también colabora para mantener uno de los compromisos del director con el estilo de Hergé: organizar la puesta en escena para que las composiciones presenten una orientación de izquierda a derecha similar a la de los dibujos originales. Como se puede comprobar en la escena antes mencionada, los movimientos de cámara y de las figuras favorecen que los personajes inicien sus intervenciones entrando o situándose a la izquierda del encuadre para terminar saliendo del mismo por la derecha. Una regla compositiva innecesaria en el caso de la adaptación cinematográfica, al no tener consecuencias sobre la dinámica de lectura de las imágenes como ocurría en los cómics, pero a la que aun así Spielberg tiende a recurrir durante toda la película en un gesto indudable de homenaje a la fuente original.

\subsection{Espacialidad: de la abstracción a la exhibición}

La movilidad de la cámara actúa también sobre el vínculo perceptivo del espectador con los espacios en los que se mueven los personajes. Spielberg aprovecha los movimientos de cámara para canalizar y hacer converger dos tendencias en apariencia contradictorias dentro de su obra: el interés por mantener personajes y acción dramática siempre en primer plano, aproximándose al estilo de Hergé, y una innegable inclinación hacia el exhibicionismo del espacio tridimensional, punto en el que la adaptación se aleja del original para espectacularizar el trabajo de diseño emprendido por el equipo de Weta.

Los espacios incluyen una batería de elementos que no solo llaman la atención por su detallado diseño, sino también por su capacidad de poner de relieve la tridimensionalidad del universo construido. Infinidad de elementos transparentes - las ventanas a través de las cuales se observa el piso de Tintín, la vitrina en la que Sakharine guarda su maqueta del barco, el vaso tras el cual se presenta por primera vez al capitán Haddockpermiten subrayar la multiplicidad de planos espaciales en los que se desarrolla la acción, cuya profundidad se abre en forma de cascada ante el espectador al moverse la cámara por ellos. También resulta recurrente el 
uso de espejos y otras superficies reflectantes a lo largo de la obra -la primera visión de la maqueta del barco por parte de Tintín en el mercadillo, que en combinación con el movimiento de la cámara permiten abrir el espacio diegético más allá de los confines del encuadre para subrayar su geometría y extensión. $\mathrm{Y}$ en las escenas nocturnas el director emplea habitualmente una iluminación dramática - los interiores de la biblioteca y la mansión, la escena del Karaboujan- que se aleja de la homogeneidad lumínica de los cómics originales, pero que realza las diversas capas y cualidades de los espacios diseñados.

Teniendo en cuenta la hipermovilidad de la cámara incluso en las escenas más estáticas de diálogo, la película exhibe un deseo inquebrantable de explorar los espacios hasta la última perspectiva, agotándolos ante los ojos del espectador. Según señala un crítico, «la cámara está en constante movimiento, por lo que lo que está al fondo inevitablemente pasará a primer plano y se apoderará del espacio, cambiará tu perspectiva y te bombardeará con nuevos planos de acción» (Edelstein, 2011: s. pág.). Así, si en relación a los personajes el movimiento de cámara tiene fines expresivos, ayudando a comunicar sus estados emocionales, en el caso de los espacios estos mismos movimientos se presentan con una cierta vocación exhibicionista.

A pesar de ello, como en la obra de Hergé, la narración fílmica nunca pierde de vista a los personajes. Según advierte Joe Letteri (Giardina, 2011: s. pág.), los dibujos de Hergé «siempre se basaban en la realidad, pero les añadía cierta estilización», dibujando «fondos muy simples porque quería mantener a sus personajes en primer plano. Jugamos con esa idea en varios sentidos». Obsérvese por ejemplo cómo resuelve Hergé la escena del descubrimiento del barco en el mercadillo: tras unas primeras imágenes en las que se presenta el puesto con todo lujo de detalles, la conversación posterior entre los personajes los muestra contra un fondo azul uniforme. A pesar de esta abstracción del espacio, el dibujante recuerda puntualmente el espacio en el que se desarrolla la acción en las viñetas donde se incorporan por primera vez Sakharine y Barnaby, manteniendo viva la experiencia espacial sin comprometer la legibilidad de las imágenes y, en consecuencia, el ritmo de lectura.

Las palabras de Letteri resultan interesantes en cuanto ponen de manifiesto, no solo el compromiso entre realismo y simplificación característico de Hergé, sino el deseo de Spielberg y su equipo de encontrar estrategias que les permitieran «jugar» con este compromiso en el marco de la adaptación cinematográfica. No es difícil comprobar que los incesantes movimientos de la cámara, aun espectacularizando el espacio, se centran en todo momento en mostrar las acciones de los personajes desde perspectivas óptimas, por lo que se podría argumentar que, a la vez que la cámara abre constantemente el espacio, solicita al espectador que preste atención a los elementos dramáticamente más relevantes del mismo.

Por la rigidez de sus encuadres, el medio cinematográfico obliga a Spielberg a tener más presente el espacio circundante en todas las imágenes, 
pero al imponer una temporalidad al visionado, también le libera de la necesidad de simplificar sus imágenes para estimular el avance en su lectura. Esto permite al director a mantener, a través de los movimientos de cámara, una postura dual respecto a la presentación del espacio, exhibiéndolo hasta el agotamiento a la vez que se hace hincapié insistentemente en la centralidad de los personajes y sus acciones. El director alcanza de este modo un compromiso similar al de Hergé entre inmersión del espectador en el espacio y primacía de la acción dramática realizada por los personajes.

\subsection{Fluidez: del corte a la transición}

Spielberg traslada esta hipermovilidad también a algunas de sus transiciones entre escenas, combinando movimientos de cámara con efectos de morphing para favorecer el traslado fluido y dinámico del espectador de un espacio-tiempo a otro dentro del relato. El resultado no ha pasado desapercibido entre críticos como Paul Bullock (2017: s. pág.), que califica estas transiciones de «proezas visuales», Manohla Dargis (2011: s. pág.), que hace referencia a ellas como «interludios de deleite cinematográfico», o David Edelstein (2011: s. pág.), que comparte su entusiasmo tras ver «el presente derritiéndose en el pasado [...], las grandes dunas del Sahara transformándose en olas gigantes a bordo de un barco pirata decimonónico», advirtiendo al lector que nunca ha visto flashbacks como estos.

Estas transiciones, avanzadas en otro registro en los títulos de crédito, permiten a Spielberg articular visualmente uno de los principales retos narrativos de la adaptación del cómic original de El secreto del Unicornio: la secuencia en la que el capitán Haddock recuerda el enfrentamiento entre su antepasado, Sir Francisco de Hadoque, y el pirata Rackham el Rojo. Tanto en el cómic como en la película, el acto de rememoración realizado por el capitán no solo implica la enunciación de sus recuerdos, sino también la reproducción mimética, teatralizada, de los actos que rememora, lo que dota a las imágenes de ambos tiempos narrativos de una gran vitalidad.

En un interesante análisis de la secuencia en el cómic original, Groensteen (2013: 107) apunta que esta estrategia se basa en un mecanismo insólito por el cual la narración «se mueve constantemente hacia detrás y hacia delante», alternando imágenes de ambos espacios temporales para construir una secuencia de gran fuerza y dinamismo en la que los lectores tienen acceso a dos registros narrativos que se complementan: por un lado, podemos «experimentar, 'vivir', los eventos que relata el capitán como si los estuviéramos presenciando directamente», asistiendo al enfrentamiento entre el caballero y el pirata; pero a la vez, este mecanismo permite al espectador compartir en paralelo tanto la emoción de Haddock, ya que «su elocuencia verbal se corresponde con la expresividad corporal», como la fascinación de sus oyentes dentro de la diégesis.

La narración nos traslada de este modo de un punto a otro, situando al espectador junto a los diferentes personajes para que establezca alianzas con 
ellos y, sobre todo, se vea contagiado por su expresividad corporal. Groensteen (2013: 107) señala que, para conseguirlo, Hergé explota al máximo el potencial del medio, lanzando una advertencia de gran relevancia:

El cine no podría hacer frente a estos continuos cambios entre el pasado y el presente; el resultado sería desarticulado y la edición perdería toda fluidez. Normalmente, en una película, cuando un personaje se convierte en el narrador de una narrativa incrustada, desaparece temporalmente de la imagen y está presente sólo a través de su voz. [...] La capacidad de complementar la narración verbal con una narración corporal y de tejer esta doble elocuencia es, entonces, peculiar del arte del cómic (y del teatro).

Pareciera que Spielberg hubiera aceptado explícitamente el reto, encontrando en el morphing y la hipermovilidad de la cámara una estrategia, también inusual en el cine, para facilitar unas transiciones fluidas entre los dos tiempos narrativos y los dos espacios de enunciación que se alternan durante la secuencia.

Spielberg utiliza el mismo recurso en otras dos ocasiones durante la película para cambiar de escenario entre secuencias diferentes. La primera transición tiene lugar al final de la primera escena en el bote salvavidas al huir del Karaboujan: tras tomar Haddock el mando de la embarcación y noquear sin querer a Tintín y Milú, Spielberg se aleja lentamente del barco hasta convertir el océano en un charco de una calle de Bruselas. La segunda llega algunas secuencias después, cuando Tintín y Haddock inician su viaje hacia Bagghar: tras ver cómo los personajes se estrechan la mano en señal de complicidad, Spielberg acerca lentamente la cámara hacia ellos hasta convertir las manos en una cadena de dunas sobre la que se observa a los personajes avanzando en camello.

Paul Bullock (2017) considera que a través de estas transiciones el director canaliza conceptos relacionados con la construcción de una comunidad entre los personajes, señalando los hitos narrativos en los que el encuentro de los mismos pasa del aislamiento a la complicidad. Pero un análisis detallado de la posición que ambas transiciones ocupan en la estructura general del relato de los cómics originales revela otro posible significado.

Como se ha avanzado, el guion de la película invierte el orden de las dos historias originales principales: la primera parte del guion se inspira de forma más o menos ordenada en acontecimientos de El secreto del Unicornio (undécimo álbum), relatando el descubrimiento del barco en el rastro, su caída y robo en casa de Tintín, la visita a la casa de Sakharine, la muerte de Barnaby y el secuestro de Tintín; y a partir de ese momento, la segunda parte el relato se inspira esencialmente en El cangrejo de las pinzas de oro (noveno álbum), que relata el encuentro y la huida con Haddock del Karaboujan, el enfrentamiento con el hidroplano en el océano, el accidente 
de avión en el Sáhara, el encuentro en el fuerte de la Legión Extranjera y el viaje a Bagghar.

Resulta interesante comprobar que las dos transiciones marcan el punto de comienzo y fin de la porción del relato fílmico en el que, una vez iniciado el bloque correspondiente a El cangrejo de las pinzas de oro, el argumento se ve en la necesidad de volver atrás para integrar dos escenas de El secreto del Unicornio que, por la inversión de sus argumentos, no podían haberse presentado al principio: la captura del carterista y la secuencia de flashbacks en los que Haddock rememora el enfrentamiento de su antepasado. Así, las transiciones marcan la porción del relato en el que ambas fuentes conviven en el guion, recurriendo Spielberg a las mismas no solo para mover al espectador de forma fluida entre los dos tiempos históricos de El secreto del Unicornio, sino también para negociar las transiciones del relato entre las dos temporalidades trastocadas de los cómics originales. Esta situación se lleva al paroxismo en las escenas de rememoración, donde las transiciones, además de fundir presente y el pasado, alternan segmentos espaciotemporales de El secreto del Unicornio - las escenas rememoradas del pasadoy El cangrejo de las pinzas de oro -los espacios del presente narrativo desde los que se enuncian esas rememoraciones: el desierto y el fuerte-.

\section{CONCLUSIONES}

En su deseo de llevar a cabo una adaptación que honrase, en palabras del director, «el aspecto distintivo de los personajes y el mundo que creó Hergé» (Brown, 2008: s. pág.), Spielberg y el equipo de Weta se enfrentaron a diversos retos estéticos y narrativos. En los apartados anteriores se han revisado las dificultades y valorado las soluciones alcanzadas por el director respecto a dos cuestiones centrales del proceso de adaptación.

Aunque la obra de Hergé está marcada por un estilo gráfico que busca alcanzar un compromiso entre realismo e iconicidad, las características propias del medio en el que trabajaba inclinaban la balanza hacia el segundo término, privilegiando el diseño icónico de unos personajes que en muchas ocasiones ocupan todo el espacio pictórico de sus viñetas. Spielberg, en cambio, al trabajar en un medio tridimensional, fotorrealista y donde los espacios tienen una mayor presencia en el encuadre, se decanta por inclinar la balanza hacia el realismo. Esta situación le obliga, además, a trasladar a los gestos de los personajes y de la cámara la carga expresiva de los diferentes signos externos - sensogramas-a los que recurre habitualmente el dibujante para expresar las emociones de sus personajes. A pesar de ello, gracias al motion capture, la adaptación consigue mantener un equilibrio con los referentes bidimensionales de la obra original, presentando unos personajes cuyos diseños evocan icónicamente a los personajes de las viñetas.

Por otro lado, si el dinamismo visual y narrativo característico de los cómics nace de un uso exhaustivo por parte del autor de una de las características específicas del medio, el multimarco (Groensteen, 2007, 
2013), Spielberg recurre igualmente a uno de los recursos específicos del medio cinematográfico para dotar a su narración de la energía y el impulso de la obra original: el movimiento de cámara. El director encuentra así en la movilidad incesante de la cámara una estrategia transversal que le permite trasladar a la narración cinematográfica no solo el dinamismo de la obra de Hergé, sino también encontrar una solución audiovisual con la que canalizar parte de la carga expresiva de las viñetas y construir transiciones ágiles entre diferentes espacios y tiempos narrativos, cuestión de especial relevancia en el proceso de adaptación de una de las secuencias más importantes de $E l$ secreto del Unicornio.

La hipermovilidad de la cámara se presenta como una solución cinematográfica acertada para llevar a la pantalla el dinamismo de las escenas basadas en las obras originales. Pero se convierte en el principal foco de las críticas cuando contagia al propio relato para convertir algunas de sus secuencias en largos pasajes de acción que, en su afán espectacular, se distancian del tono de la acción en la obra original, caracterizado por la continua sucesión de peripecias, pero no de proezas físicas. Será precisamente en estos pasajes, en los que el director se aleja de la acción «pedestre» de la obra original para poner en escena una sucesión de hazañas «de altos vuelos» (Rainer, 2011: s. pág.), donde la película demuestra sus mayores licencias y deficiencias en el proceso de adaptación, decepcionando a muchos amantes de los cómics de Hergé.

En estos pasajes, el estilo de la película no solo se «distancia del pragmatismo y eficacia de la línea clara», como bien apunta Jordi Revert (2013: 25), sino que llega a quebrar los compromisos compositivos, expresivos y narrativos asumidos por lo general con la obra original. Y, a pesar de concentrarse principalmente en el último cuarto de la película, introducen tanto ruido que llevan a algunos críticos a condenar toda la película por convertir «una obra de arte sutil, intrincada y hermosa en el típico blockbuster grandilocuente» (Nicholas Lezard, 2011: s. pág.).

Posiblemente, la tecnología digital empleada por Spielberg, como apunta Jordi Revert (2013: 24), «invitaba al equipo artístico del proyecto a (re)imaginar la acción en términos de un gran espectáculo visual al que los comics originales no acostumbraban a prestarse», lo que despertaría las mayores objeciones por parte de la crítica. Pero la decisión del director demostraría ser un movimiento comercial rentable ${ }^{2}$ para alcanzar a un público global a través de una narrativa propia del blockbuster de acciónaventura y cumpliendo la «promesa de entretenimiento familiar de alta calidad y cargado de emociones» que Hunter (2017: 213) identifica como

\footnotetext{
${ }^{2}$ La película alcanzó una recaudación en taquilla de casi 374 millones de dólares. Véase «The Adventures of Tintin», Box Office Mojo, s. pág. [En línea: https://www.boxofficemojo.com/title/tt0983193/?ref =bo se r 1. Fecha de consulta: 18/02/2021].
} 
característica de la marca o «reputación altamente comercializable» de Spielberg.

A pesar de que el concepto de fidelidad es habitualmente aplicado por la crítica a la hora de valorar toda adaptación, Hunter (2017: 215) apunta que, en el caso de las obras de Spielberg, al que describe como un «autor de la adaptación», es importante valorar sus adaptaciones por el modo en que encajan en el «canon Spielberg», resultando desde este punto de vista menos importante la comparación con el material original que el resultado final que ha obtenido tras el proceso, lo que se convierte en «el marco definitorio de su recepción y horizonte de interpretación» (Hunter, 2017: 213). En este sentido, Las aventuras de Tintín: El secreto del unicornio se presenta como un filme indiscutiblemente spielbergiano, como queda patente en las innumerables críticas que recurren inevitablemente a los diferentes títulos que componen la saga de Indiana Jones como punto de referencia para valorar y situar frente a sus lectores la película del director, que de seguir adelante con los planes, podría convertirse en el punto de inicio de una nueva franquicia.

En cualquier caso, más allá de comparaciones y valoraciones comerciales, si bien quizás la obra «imita demasiado a una película de acción tradicional», como señala Roger Ebert (2011: s. pág.), también es cierto que Spielberg no se ha centrado en copiar o traducir al cine «el aspecto literal de las tiras de Tintín, sino la sensación» que producen. Y en este sentido, la película se presenta como una arriesgada e interesante propuesta de adaptación que cuenta con múltiples logros y permite ahondar en el estudio de los compromisos, las dificultades y las posibilidades de la adaptación del cómic al medio cinematográfico.

\section{BIBLIOGRAFÍA CITADA}

Bartlett, Myke (2012), «Drawn into Motion», Screen Education, 65, págs. 7-17.

Berlatsky, Noah (2011), «How Spielberg Handles the Racial Problems of the 'Tintin' Books», The Atlantic, s. pág. [En línea: https://www.theatlantic.com/entertainment/archive/2011/12/ how-spielberg-handles-the-racial-problems-of-the-tintinbooks/250382. Fecha de consulta: 20/02/2021].

Bettinger, Brendan (2011), «Steven Spielberg Talks About the Motion Capture of THE ADVENTURES OF TINTIN», Collider, s. pág. [En línea: https://collider.com/steven-spielberg-talks-about-the-motioncapture-of-the-adventures-of-tintin. Fecha de consulta: 20/02/2021]. BROWN, Marc (2008), «Blistering barnacles! It's Spielberg's new Tintin», The Guardian, s. pág. [En línea: https: / / www. theguardian.com/film/2008/mar/28/books.news. Fecha de consulta: 18/02/2021].

Bullock, Paul (2017), «Painting with Pixels: Spielberg's Tintin», Medium, s. pág. [En línea: https://medium.com/from-director-steven- 
spielberg/painting-with-pixels-spielbergs-tintin-dfbb57341f69. Fecha de consulta: 18/02/2021].

CABIN, Chris (2012), «Steven Spielberg's The Adventures of Tintin on Paramount Blu-ray», Slant, s. pág. [En línea: https: / / www.slantmagazine.com/dvd/the-adventures-of-tintin-bd/. Fecha de consulta: 01/03/2021].

CARTER, Chris (2019), «Hyper-Realism in The Adventures of Tintin», International Journal of Computer Graphics \& Animation, 9(4), págs. 1-12.

Corliss, Richard (2011), «Spielberg's 3-D Cartoon Adventure: It's Tintinastic!», Time, s. pág. [En línea: https://entertainment.time.com/2011/12/21/spielbergs-3-dcartoon-adventure-its-tintinastic/. Fecha de consulta: 18/02/2021].

DARGIS, Manohla (2011), «Intrepid Boy on the Trail of Mysteries», The New York Times, s. pág. [En línea: https: / / www.nytimes.com/2011/12/21/movies/the-adventuresof-tintin-by-steven-spielberg-review.html. Fecha de consulta: 24/04/2021].

Dorfman, Daniela (2020), «El exotismo del “otro”: chinos, rusos, y africanos en tres álbumes de Georges Remi», Escritura e Imagen, 16, págs. 213-225.

EberT, Roger (2011), «Tintin! Tonnerre de Brest! Mille sabords!», RogerEbert.com, $\mathrm{s}$ [En pág. línea: https://www.rogerebert.com/reviews/the-adventures-of-tintin2011. Fecha de consulta: 18/02/2021].

EDElSTEIN, David (2011), «The Adventures of Tintin», New York Magazine, s. pág. [En línea: https://nymag.com/listings/movie/adventures-oftintin-the/. Fecha de consulta: 18/02/2021].

Elvy, Craig (2020), «Tintin: Peter Jackson's Original Trilogy Plan (\& Why It Hasn't Happened)», Screen Rant, s. pág. [En línea: https://screenrant.com/tintin-peter-jackson-trilogy-plans-delayreason/. Fecha de consulta: 24/04/2021].

FARr, Michael (2001), Tintin. The Complete Companion, London, Jon Murray.

FreI, Vincent (2011), «THE ADVENTURES OF TINTIN: Matt Aitken VFX Supervisor - Weta Digital», $A R T$ of VFX, s. pág. [En línea: https://www.artofvfx.com/the-adventures-of-tintin-matt-aitkensuperviseur-vfx-weta-digital/. Fecha de consulta: 20/02/2021].

Galloway, Stephen (2011), "The Titans Behind 'The Adventures of Tintin'», The Hollywood Reporter, s. pág. [En línea: https: / /www.hollywoodreporter.com/news/adventures-tintinsteven-spielberg-peter-jackson-250102. Fecha de consulta: 19/02/2021].

GaSCA, Luis y Roman Gubern (2001), El discurso del cómic, Madrid, Cátedra. 
Geraghty, Lincoln (2017), «Spielberg, Fandom, and the Popular Appeal of His Blockbuster Movies», en N. Morris (ed.), A Companion to Steven Spielberg, West-Sussex, Wiley-Blackwell, págs. 452-465.

Giardina, Carolyn (2011), «'The Adventures of Tintin': What James Cameron Showed Spielberg and Jackson», The Hollywood Reporter, s. $\quad$ pág. [En línea: https://www.hollywoodreporter.com/news/adventures-tintinjames-cameron-spielberg-jackson-250106. Fecha de consulta: 19/02/2021].

Groensteen, Thierry (2007), The System of Comics, Jackson, University Press of Mississippi.

Groensteen, Thierry (2013), Comics and Narration, Jackson, University Press of Mississippi.

Grossman, Lev (2011), «It's Tintin Time!», Time, s. pág. [En línea: http://content.time.com/time/magazine/article/0,9171,20973731,00.html. fecha de consulta: 02/04/2021].

GuISE, Chris (2011), Artbook. Las aventuras de Tintin, Barcelona, Zephyrum Ediciones.

Hergé (1990a), El cangrejo de las pinzas de oro, Barcelona, Editorial Juventud. HergÉ (1990b), El secreto del Unicornio, Barcelona, Editorial Juventud.

HeRGÉ (1990c), El tesoro de Rackham el Rojo, Barcelona, Editorial Juventud. Hergé (1991), «Cómo nace una aventura de Tintín», en VV.AA., El museo imaginario de Tintín, Barcelona, Editorial Juventud, págs. 10-19.

HunTeR, I.Q. (2017), «Spielberg and Adaptation», en Nigel Morris (ed.), A Companion to Steven Spielberg, West-Sussex, Wiley-Blackwell, págs. 212-226.

LeZARD, Nicholas (2011), «How could they do this to Tintin?», The Guardian, $\quad$ s. $[\mathrm{En}$ pág. línea: https://www.theguardian.com/culture/2011/oct/18/how-coulddo-this-tintin. Fecha de consulta: 04/03/2021].

LOFFICIER, Jean-Marc y Randy Lofficier (2002), The Pocket Essential Tintin, Harpenden, Pocket Essentials.

LyONS, Margaret (2011), «The Adventures of Tintin Is a Lot Like Indiana Jones», Vulture, s. [En línea: https: / /www.vulture.com/2011/12/tintin-indiana-jones.html. Fecha de consulta: 02/05/2021].

O’HeHIR, Andrew (2011), «"The Adventures of Tintin”: Spielberg's weird action cartoon», Salon, s. pág. [En línea: https://www.salon.com/2011/12/20/the_adventures_of_tintin_ spielbergs_weird_action_cartoon. Fecha de consulta: 27/04/2021].

Mccloud, Scott (1993), Understanding Comics. The Invisible Art, New York, HarperCollins.

NGUYEN, Nick (2012), «The Adventures of Tintin: The Secret of the Unicorn (Steven Spielberg, 2011)», European Comic Art Vol, 5(1), pág. [En 108-117 línea: 
https://www.academia.edu/2910589/The_Adventures_of_Tintin_ The_Secret_of_the_Unicorn_Steven_Spielberg_2011_. Fecha de consulta: 19/02/2021].

RAINER, Peter (2011), «The Adventures of Tintin: movie review», The Christian Science Monitor, s. pág. [En línea: https://www.csmonitor.com/The-

Culture/Movies/2011/1221/The-Adventures-of-Tintin-moviereview-VIDEO. Fecha de consulta: 19/02/2021].

REVERT, Jordi (2013), «Tintín o el trazo difícil: un viaje accidentado al 'mainstream' del cine», L'Atalante: revista de estudios cinematográficos, 16, págs. 20-26.

SCReECH, Matthew (2005), Masters of the Ninth Art: Bandes Dessinées and Franco-Belgian Identity, Liverpool, Liverpool University Press.

Sterckx, Pierre (1991), "Tintín, trazo a trazo», en VV.AA., El museo imaginario de Tintín, Barcelona, Editorial Juventud, págs. 20-25.

Weber, Bill (2011), «Review: The Adventures of Tintin», Slant, s. pág. [En línea: https://www.slantmagazine.com/film/the-adventures-oftintin/. Fecha de consulta: 01/03/2021].

Fecha de recepción: 09/03/21.

Fecha de aceptación: 10/05/21. 